\title{
Multicentric Glioma Develops via a Mutant IDH1-Independent Pathway: Immunohistochemical Study of Multicentric Glioma
}

\author{
Vega Karlowee $^{a}$ Vishwa Jeet Amatya $^{b}$ Hirofumi Hirano ${ }^{d}$ Takeshi Takayasu $^{a}$ \\ Ryo Nosaka $^{a}$ Manish Kolakshyapatia Masako Yoshihiro ${ }^{a}$ Yukio Takeshima $^{b}$

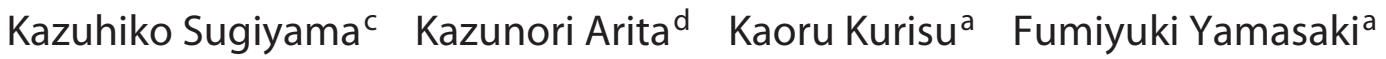 \\ Departments of a Neurosurgery and bathology, Graduate School of Biomedical and Health Sciences, Hiroshima \\ University, and ${ }^{\mathrm{C} D e p a r t m e n t}$ of Clinical Oncology and Neuro-Oncology Program, Hiroshima University Hospital, \\ Hiroshima, and d Department of Neurosurgery, Graduate School of Medical and Dental Sciences, Kagoshima \\ University, Kagoshima, Japan
}

\section{Key Words}

Multicentric glioma $\cdot$ Mutant IDH1 · ATRX $\cdot 1$ p19q loss

\begin{abstract}
Multicentric gliomas are very rare. Due to differences in their tumor types they remain enigmatic. We focused on the pathogenesis of multicentric gliomas and compared their immunoprofile with that of solitary gliomas. This retrospective study included 6 males and 8 females with multicentric glioma (8 glioblastomas, 2 anaplastic astrocytomas, 4 diffuse astrocytomas). Their age ranged from 27 to 75 years and all were treated between 2004 and June 2015. The expression of mutant isocitrate dehydrogenase 1 (IDH1), a-thalassemia X-linked intellectual disability (ATRX), p53, phosphatase and tensin homolog (PTEN), and epidermal growth factor receptor (EGFR) was examined immunohistochemically; for $1 p 19 q$ analysis we used fluorescence in situ hybridization (FISH). In all patients, immunohistochemical staining was negative for mutant IDH1 and cytoplasmic PTEN; only 1 patient (7.1\%) manifested nuclear PTEN positivity. FISH for $1 \mathrm{p} 19 \mathrm{q}$ codeletion was negative in all 9 examined samples; 5 of 14 specimens (35.7\%) were p53-positive, 9 (64.3\%) were EGFR-posi-
\end{abstract}

tive, and 4 (28.6\%) were ATRX-negative. The MIB-1 labeling index was $0.9-15.6 \%$ for grades II and III, and ranged between 17.3 and $52.4 \%$ for glioblastoma. Our results suggest that the pathogenesis of multicentric gliomas is different from the mutant IDH1-R132H pathogenesis of lower-grade glioma and secondary glioblastomas. More studies are needed to confirm the molecular mechanisms underlying the pathogenesis of multicentric glioma. @ $2016 \mathrm{~S}$. Karger AG, Basel

\section{Introduction}

Multicentric glioma, defined as multiple, widely separated brain tumor masses in different lobes or different hemispheres, is not spread via pathways along commissural or cerebrospinal fluid channels or local metastases via satellite formation [1]. Among gliomas, multicentric glioma is very rare [1-5] and its incidence depends on the diagnostic criteria and techniques used [e.g. computed tomography, magnetic resonance imaging (MRI), autopsy].

Different from solitary gliomas, the pathogenesis of multicentric gliomas is not well understood $[1,2,4-8]$

\section{KARGER}

(c) 2016 S. Karger AG, Basel

E-Mail karger@karger.com

www.karger.com/pat
Fumiyuki Yamasaki, MD, PhD

Department of Neurosurgery, Graduate School of Biomedical and Health Sciences Hiroshima University, 1-2-3 Kasumi, Minami-ku

Hiroshima 734-8551 (Japan)

E-Mail fyama@hiroshima-u.ac.jp 
because most of the earlier studies focused on imaging findings and clinical outcomes. Although no detailed molecular findings on multicentric glioma have been reported, new insights into the molecular background of brain tumors, including gliomas, have yielded a better understanding of glioma's biological nature $[9,10]$. In glioblastoma patients, mutant isocitrate dehydrogenase 1 (IDH1) is the most powerful prognostic factor and is useful for the differentiation between primary and secondary glioblastomas [11-13]. Lower-grade gliomas are classified into 3 subgroups: types 1 and 2 are mutant IDH1- or mutant IDH2-positive, and type 3 is mutant IDH1- or mutant IDH2-negative $[14,15]$.

We profiled immunohistochemical staining of 14 multicentric gliomas and compared them with those of the better-understood solitary tumors. We report that the pathogenesis of multicentric gliomas is mutant IDH1-independent.

\section{Patients and Methods}

This retrospective study was approved by our institutional review board. To protect patient privacy, we removed all identifiers from our records upon completion of the analysis.

Our study subjects, 6 males and 8 females (age: $27-75$ years), were treated in our institution between 2004 and July, 2015. The diagnostic criteria was based on Batzdorf and Malamud [1], and we excluded gliomatosis cerebri cases. When 1.5-tesla (until June 2006) or 3.0-tesla (after July 2006) MRI studies showed multiple brain tumors with no connecting signal alteration, the glioma type was confirmed histopathologically [16]. MRI included nonenhanced T1-weighted and T2-weighted fluid-attenuated inversion recovery (FLAIR), and transverse, sagittal, and coronal enhanced T1-weighted images acquired after the intravenous administration of a gadolinium-based contrast medium. The MR characteristics were defined as FLAIR-high (no gadolinium enhancement) and as focally, diffusely, and ring enhanced. In all but 2 patients the analysis was based on one lesional biopsy performed at the primary operation. In the other 2 patients it was based on the analysis of 2 different lesions, both of which were diagnosed as glioblastoma. All samples were stained immunohistochemically; 11 samples from 9 patients underwent fluorescence in situ hybridization (FISH) due to the limited availability of tissue. The tumor specimens were obtained by surgical biopsy in all cases and fixed in $10 \%$ formalin before being embedded in paraffin and stained with hematoxylin-eosin for standard histologic diagnosis.

\section{Immunohistochemical Staining}

Immunohistochemical staining for all antibodies except p53 was performed in an automated immunostainer (BenchMark GX; Ventana, Tucson, Ariz., USA). Mutant IDH1, a-thalassemia Xlinked intellectual disability (ATRX), and epidermal growth factor receptor (EGFR) were detected with the iView Detection Kit using cell conditioning (CC)-1. Mutant IDH1 and EGFR were incubated at $37^{\circ} \mathrm{C}$ for $1 \mathrm{~h}$ and $32 \mathrm{~min}$, respectively, with neither amplification nor blocking; ATRX was incubated at $37^{\circ} \mathrm{C}$ for 32 min with amplification and blocking. The primary antibodies were anti-human IDH1 R132H (1:100, Dianova, Hamburg, Germany), anti-ATRX (1:200; Sigma-Aldrich, St. Louis, Mo., USA), and anti-human wild-type EGFR (1:50; Dako, Glostrup, Denmark). The positive control for mutant IDH1 was oligodendroglioma (WHO grade II; IDH R132H-mutant, 1p/19q-codeleted), based on the 2016 WHO classification [17]. As for ATRX, the negative control was diffuse astrocytoma (WHO grade II; IDH R132H-mutant case) (online suppl. figure; see www.karger.com/doi/10.1159/000447951 for all online suppl. material).

Immunostaining for phosphatase and tensin homolog (PTEN) was done with the OptiView Detection Kit with $\mathrm{CC}-1$ at $37^{\circ} \mathrm{C}$ incubation for $32 \mathrm{~min}$, HQ universal linker, and HRP multimer for 8 min without amplification. Anti-human PTEN (1:100, Dako) was used as the primary antibody. The antibody for $\mathrm{p} 53$ was prepared using anti-human $\mathrm{p} 53$ protein (1:100, Dako) [18]. The antibody against Ki-67/MIB-1 was an anti-human Ki-67 antigen clone MIB-1 (1:25, Dako).

Immunohistochemical staining was evaluated according to established criteria. Positivity for mutant IDH1 was recorded when there was strong cytoplasmic staining [19], for p53 and ATRX when more than $10 \%$ of the tumor revealed nuclear staining [ 18 , 20]. PTEN positivity was based on the cytoplasmic staining intensity and pattern [21], and EGFR positivity was based on the grade of membrane and/or cytoplasm staining [22]. The MIB-1 labeling index evaluation was based on nuclear staining of the tumor cell [23].

\section{FISH}

Sample slides ( $4 \mu \mathrm{m}$ in thickness) were deparaffinized and dehydrated with xylene and absolute alcohol $(\times 3)$, respectively. At room temperature, they were pretreated with $0.2 \mathrm{~N} \mathrm{HCl} \mathrm{for} 20 \mathrm{~min}$, washed twice with SSC buffer (Life Technologies, New York, N.Y., USA), and incubated at $80^{\circ} \mathrm{C}$ for $30 \mathrm{~min}$ in pretreatment solution (Abbott Molecular Inc., Abbot Park, Ill., USA). After washing with SSC they were incubated at $37^{\circ} \mathrm{C}$ for 5 min with pepsin (Dako). Hybridization was at $75^{\circ} \mathrm{C}$ for $5 \mathrm{~min}$ followed by $37^{\circ} \mathrm{C}$ for $16 \mathrm{~h}$ with Vysis 1p36/1q25 and 19q13/19p13 FISH probe kit (Abbott Laboratories, Ill., USA). After washing with $0.3 \%$ nonionic detergent (Nacalai Tesque Inc., Kyoto, Japan) at 37 and $65^{\circ} \mathrm{C}$ for 1 and $8 \mathrm{~min}$, respectively, and the application of DAPI (Life Technologies), the slides were evaluated under an IX81 Olympus fluorescent microscope using Meta Imaging series software (Version 7.1).

The results were evaluated based on existing criteria [24].

\section{Results}

MRI and histological findings are summarized in table 1. Of the 14 patients; 8 were diagnosed as glioblastoma (grade IV), 2 as anaplastic astrocytoma (grade III), and 4 as diffuse astrocytoma (grade II). Two patients presented with 4 lesions and the others with 2-3 lesions. Half of the patients showed different imaging characteristics among the lesions. In one patient with 4 lesions, one was ring enhanced and the others were diffusely enhanced. In other 
Table 1. Patient data

\begin{tabular}{|c|c|c|c|c|c|}
\hline Case & $\begin{array}{l}\text { Age, } \\
\text { years }\end{array}$ & Sex & Location & MRI characteristics & Pathologic diagnosis \\
\hline 1 & 75 & M & $\begin{array}{l}\text { R. temporal } \\
\text { L. parietal }\end{array}$ & $\begin{array}{l}\text { Ring enhanced } \\
\text { FLAIR-high }\end{array}$ & Glioblastoma \\
\hline 2 & 68 & $\mathrm{~F}$ & $\begin{array}{l}\text { R. temporal } \\
\text { L. parietal } \\
\text { R. parietal } \\
\text { L. temporal }\end{array}$ & $\begin{array}{l}\text { Diffuse enhanced } \\
\text { Diffuse enhanced } \\
\text { Diffuse enhanced } \\
\text { Diffuse enhanced }\end{array}$ & Glioblastoma \\
\hline 3 & 73 & M & $\begin{array}{l}\text { R. temporal } \\
\text { R. frontal } \\
\text { R. parietal } \\
\text { Corpus callosum }\end{array}$ & $\begin{array}{l}\text { Ring enhanced } \\
\text { Diffuse enhanced } \\
\text { Diffuse enhanced } \\
\text { Diffuse enhanced }\end{array}$ & Glioblastoma \\
\hline 4 & 61 & $\mathrm{~F}$ & $\begin{array}{l}\text { R. parietal } \\
\text { L. parietal } \\
\text { L. temporal }\end{array}$ & $\begin{array}{l}\text { Ring enhanced } \\
\text { Ring enhanced } \\
\text { FLAIR-high }\end{array}$ & Glioblastoma \\
\hline $\begin{array}{l}5 a \\
5 b\end{array}$ & 66 & $\mathrm{~F}$ & $\begin{array}{l}\text { L. parietal } \\
\text { L. frontal }\end{array}$ & $\begin{array}{l}\text { Ring enhanced } \\
\text { Ring enhanced }\end{array}$ & $\begin{array}{l}\text { Glioblastoma } \\
\text { Glioblastoma }\end{array}$ \\
\hline 6 & 54 & $\mathrm{~F}$ & $\begin{array}{l}\text { L. temporal } \\
\text { R. frontal }\end{array}$ & $\begin{array}{l}\text { Ring enhanced } \\
\text { FLAIR-high }\end{array}$ & Glioblastoma \\
\hline 7 & 65 & M & $\begin{array}{l}\text { R. frontal } \\
\text { R. parietal }\end{array}$ & $\begin{array}{l}\text { Ring enhanced } \\
\text { Ring enhanced }\end{array}$ & Glioblastoma \\
\hline $\begin{array}{l}8 \mathrm{a} \\
8 \mathrm{~b}\end{array}$ & 44 & $\mathrm{~F}$ & $\begin{array}{l}\text { R. frontal } \\
\text { L. frontal }\end{array}$ & $\begin{array}{l}\text { Ring enhanced } \\
\text { Ring enhanced }\end{array}$ & $\begin{array}{l}\text { Glioblastoma } \\
\text { Glioblastoma }\end{array}$ \\
\hline 9 & 71 & M & $\begin{array}{l}\text { Corpus callosum } \\
\text { R. parietal } \\
\text { R. temporal }\end{array}$ & $\begin{array}{l}\text { Ring enhanced } \\
\text { Ring enhanced } \\
\text { Ring enhanced }\end{array}$ & Anaplastic astrocytoma \\
\hline 10 & 70 & $\mathrm{~F}$ & $\begin{array}{l}\text { R. frontal } \\
\text { R. temporal } \\
\text { R. parietal }\end{array}$ & $\begin{array}{l}\text { Focal enhanced } \\
\text { FLAIR-high } \\
\text { FLAIR-high }\end{array}$ & Anaplastic astrocytoma \\
\hline 11 & 56 & $\mathrm{M}$ & $\begin{array}{l}\text { L. frontal } \\
\text { L. parietal } \\
\text { L. occipital }\end{array}$ & $\begin{array}{l}\text { FLAIR-high } \\
\text { FLAIR-high } \\
\text { FLAIR-high }\end{array}$ & Diffuse astrocytoma \\
\hline 12 & 27 & $\mathrm{~F}$ & $\begin{array}{l}\text { L. thalamus } \\
\text { L. frontal }\end{array}$ & $\begin{array}{l}\text { FLAIR-high } \\
\text { FLAIR-high }\end{array}$ & Diffuse astrocytoma \\
\hline 13 & 31 & M & $\begin{array}{l}\text { L. frontal } \\
\text { R. temporal }\end{array}$ & $\begin{array}{l}\text { Focal enhanced } \\
\text { FLAIR-high }\end{array}$ & Diffuse astrocytoma \\
\hline 14 & 58 & $\mathrm{~F}$ & $\begin{array}{l}\text { L. temporal } \\
\text { L. thalamus }\end{array}$ & $\begin{array}{l}\text { FLAIR-high } \\
\text { FLAIR-high }\end{array}$ & Diffuse astrocytoma \\
\hline
\end{tabular}

patients, 2-3 lesions manifested either as both ring enhanced and FLAIR-high $(\mathrm{n}=3)$ or focally enhanced and FLAIR-high $(\mathrm{n}=1)$.

The immunohistochemical staining results are summarized in table 2 . All patients were negative for mutant IDH1 (16 tumor specimens). One patient (7.1\%) mani- fested nuclear positivity for PTEN; it was negative in the cytoplasm of all 16 tumor samples. FISH results for $1 \mathrm{p} 19 \mathrm{q}$ codeletion were negative in all 9 studied cases (11 tumor specimens); p53 was positive in 5 of 14 patients (35.7\%; 6 of 16 samples) and ATRX was negative in 4 of 14 patients (28.6\%, 6 of 16 specimens). EGFR was overexpressed in 9 
Table 2. Results of immunohistochemical staining and FISH analysis

\begin{tabular}{|c|c|c|c|c|c|c|c|c|}
\hline \multirow[t]{2}{*}{ Case } & \multicolumn{7}{|c|}{ Immunohistochemical staining } & \multirow{2}{*}{$\begin{array}{l}\text { FISH } \\
1 \mathrm{p} 19 \mathrm{q} \\
\text { code- } \\
\text { letion }\end{array}$} \\
\hline & $\begin{array}{l}\text { MIB-1 } \\
\text { LI, \% }\end{array}$ & $\begin{array}{l}\text { mutant } \\
\text { IDH1 }\end{array}$ & ATRX & p53 & EGFR & $\begin{array}{l}\text { PTEN } \\
\text { (cytoplasmic) }\end{array}$ & $\begin{array}{l}\text { PTEN } \\
\text { (nuclear) }\end{array}$ & \\
\hline 1 & 17.3 & - & + & + & - & - & - & - \\
\hline 2 & 19.4 & - & + & - & - & - & - & ND \\
\hline 3 & 40.2 & - & - & - & + & - & - & ND \\
\hline 4 & 45.9 & - & + & - & - & - & - & - \\
\hline $5 a$ & 12.1 & - & + & - & + & - & - & - \\
\hline $5 b$ & 17.8 & - & - & - & + & - & - & - \\
\hline 6 & 16.5 & - & + & + & + & - & - & - \\
\hline 7 & 26.9 & - & - & + & - & - & - & - \\
\hline $8 a$ & 18.4 & - & + & + & + & - & - & - \\
\hline $8 b$ & 52.4 & - & + & + & + & - & - & - \\
\hline 9 & 15.3 & - & + & - & + & - & - & ND \\
\hline 10 & 15.6 & - & + & - & + & - & - & - \\
\hline 11 & 1.4 & - & - & - & + & - & - & - \\
\hline 12 & 6.2 & - & + & - & - & - & + & ND \\
\hline 13 & 0.9 & - & + & - & - & - & - & ND \\
\hline 14 & 1.6 & - & + & + & + & - & - & - \\
\hline
\end{tabular}

of 14 patients ( $64.3 \%, 6$ of 16 samples). The MIB- 1 labeling index ranged between 0.9 and $15.6 \%$ for grade II and III tumors, and in the range of $17.3-52.4 \%$ for glioblastoma.

Representative cases of diffuse astrocytoma, anaplastic astrocytoma, and glioblastoma are shown in figures 1-3, respectively.

\section{Discussion}

We focused on molecules that play an important role in the pathogenesis of glioma and included mutant IDH1, ATRX, EGFR, p53, and the 1p19q codeletion status [10, $11,20,25-27]$. IDH1 mutations are thought to occur at the early stage of most lower-grade gliomas and secondary glioblastomas [11, 12, 27-29], contrary to primary glioblastomas where negativity for mutant IDH1 expression is primarily observed $[10,30]$. None of our patients with grade IV or lower-grade multicentric gliomas expressed mutant IDH1. Furthermore, we found no ATRX immunonegativity, although the majority of secondary glioblastomas and lower-grade astrocytomas exhibit ATRX mutation [11, 31, 32].

Our findings suggest that the pathogenesis of multicentric lower-grade gliomas and multicentric glioblastomas is mutant IDH1 (R132H)-independent as opposed to the common solitary low-grade glioma, and that they most likely exhibit characteristics of primary glioblastoma. A study of 258 glioblastomas by Liu et al. [33] reported that multicentric glioblastoma was dominated by the mesenchymal subtype, without mutation in IDH1 and ATRX, contrary to the common proneural or G-CIMP subtype. They also have poorer survival than the solitary ones. Although different methods were applied, our IDH1 and ATRX profiles in glioblastoma were comparatively consistent with the above study.

Considering the characteristic impact of $1 \mathrm{p} 19 \mathrm{q}$ codeletion in oligodendroglioma $[11,17,25]$, we performed FISH analysis of viable cases. None of the analyzed cases showed 1p19q codeletion, indicating that multicentric gliomas are not of oligodendroglial origin $[11,34,35]$.

We also found that most of our multicentric gliomas showed no or low $\mathrm{p} 53$ staining. This result was in contrast to other diffuse astrocytomas and secondary glioblastomas with mutant IDH1 [11, 36-38].

Studies have classified lower-grade gliomas (grades II and III) into 3 subgroups: type $1=$ mutant IDH1- or mutant IDH2-positive with $1 \mathrm{p} 19 \mathrm{q}$ codeletion (oligodendroglial tumor group), type 2 = mutant IDH1- or mutant IDH2-positive with ATRX and/or p53 mutation (astrocytic tumor group), and type 3 = mutant IDH1 - or mutant IDH2-negative, i.e. wild-type IDH1/IDH2 with EGFR activation or PTEN inactivation $[14,15]$. All of our 

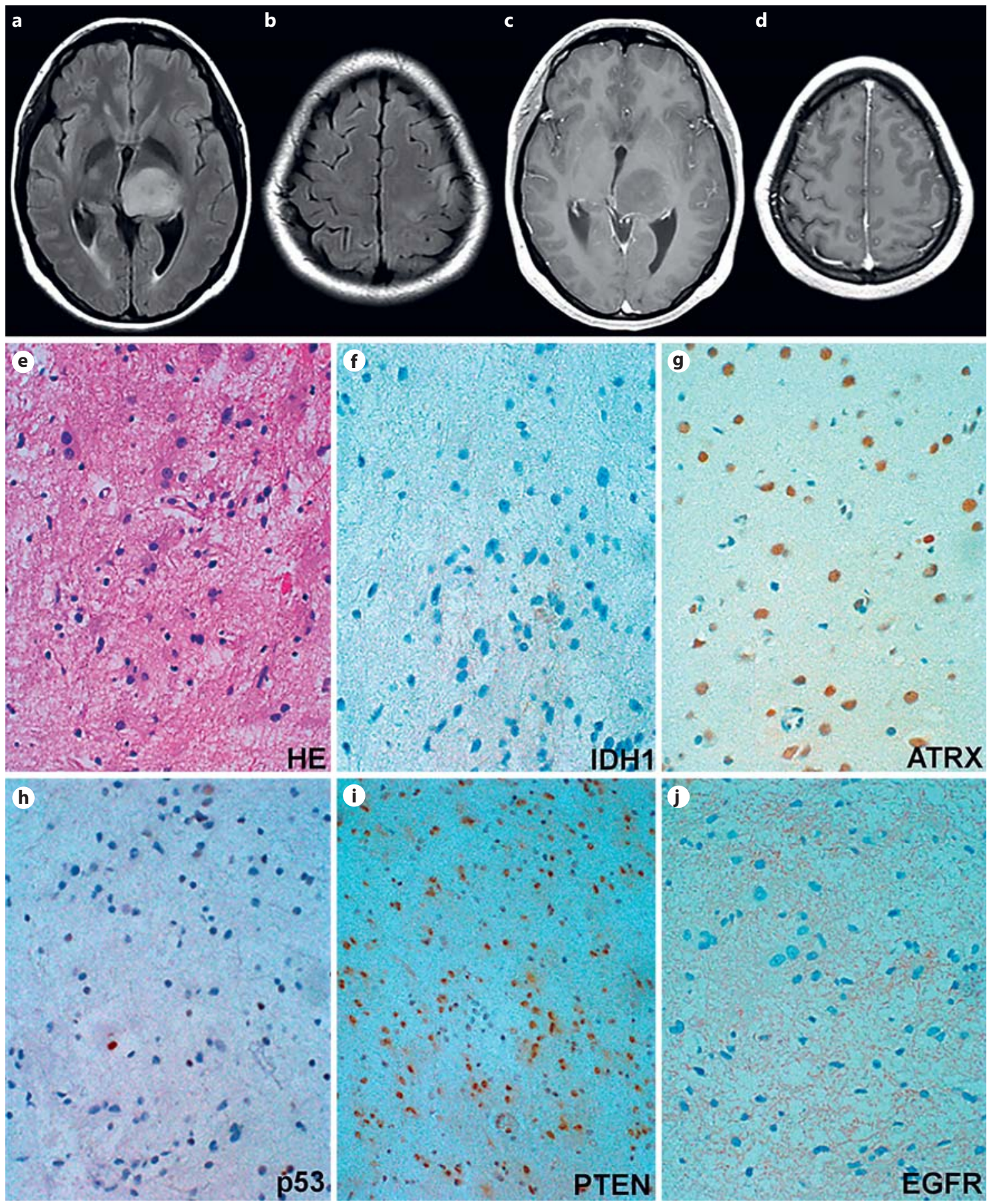

Fig. 1. Diffuse astrocytoma in a 27-year-old female. a, b Note two solid masses in the left thalamus and the left frontal lobe on FLAIR images. c, d Neither mass is enhanced on the T1-weighted gadolinium-enhanced scans. e Tissue biopsy of the mass in the left thalamus revealed a low-cellularity astrocytic tumor (HE). f Mutant
IDH1-R132H immunohistochemical staining was negative. ATRX staining was positive (g) and p53 was negative (h). Nuclear PTEN staining was positive (i), and EGFR appeared negative (j). All magnifications $\times 400$. 

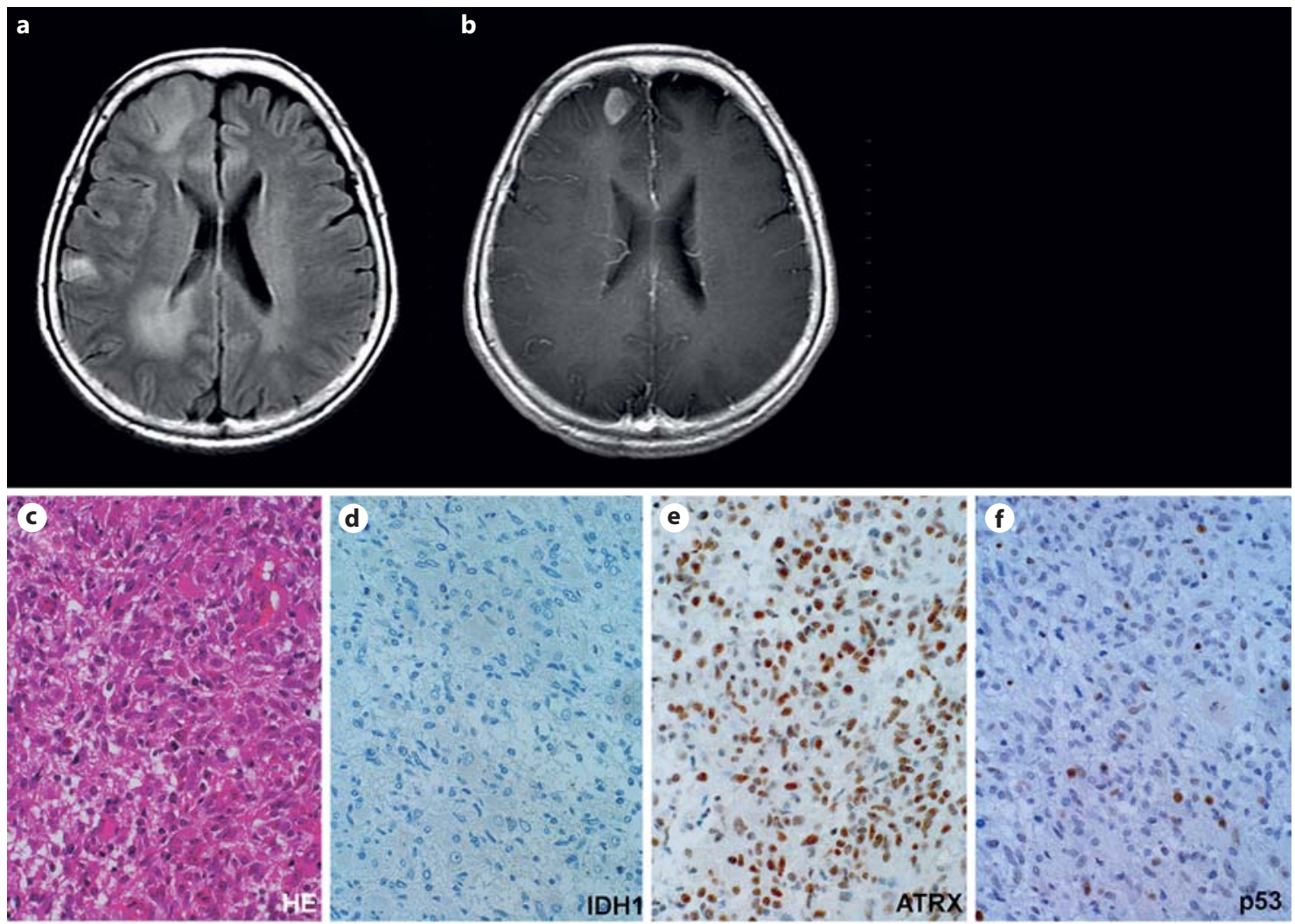
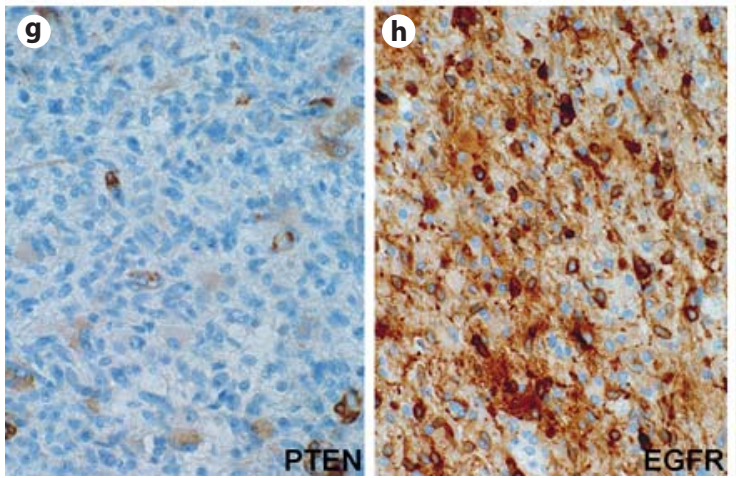
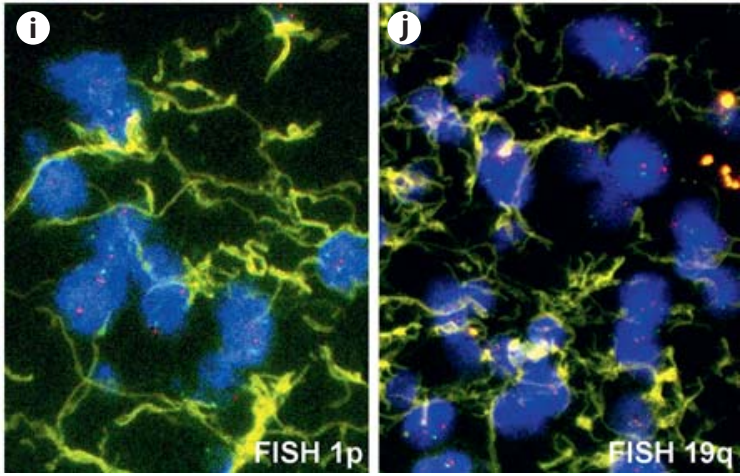

Fig. 2. Anaplastic astrocytoma in a 70-year-old female. There are 3 high-intensity masses in the right frontal-, parietal-, and temporal lobe on FLAIR images. a, b The right frontal mass shows focal enhancement on the T1-weighted gadolinium-enhanced scan. c Tissue biopsy of the frontal mass revealed predominantly anaplastic and hyperchromatic nuclei with atypical mitoses (HE). d Mutant IDH1-R132H staining was negative. Immunohistochemical staining for ATRX was positive (e); p53 and PTEN were stain-negative (f, $\mathbf{g})$. There was diffuse EGFR overexpression (h). FISH showed no codeletion of chromosome $1 \mathrm{p}$ and $19 q(\mathbf{i}, \mathbf{j})$. All magnifications $\times 400$.
Fig. 3. Glioblastoma in a 44-year-old female. Two masses in the left and right frontal lobe were high-intense on FLAIR images (a) with ring enhancement on T1-weighted gadolinium-enhanced scans (b). Tissue biopsy of the mass in the left (c) and right frontal lobe (d) (HE) showed pleomorphic and anaplastic tumor nuclei with frequent mitoses. Immunohistochemical staining results were the same for both lesions; mutant IDH1-R132H was negative in the left (e) and right (f) frontal tumor. ATRX was positive in the left (g) and right mass (h) as was p53 (left, i; right, j). PTEN staining was negative (left, k; right, I). EGFR was overexpressed (left, $\mathbf{m}$; right, $\mathbf{n}$ ). FISH analysis of chromosome 1p (left, o; right, p) and $19 \mathrm{q}$ (left, q; right $\mathbf{r}$ ) showed no codeletion in both lesions. All magnifications $\times 400$. 

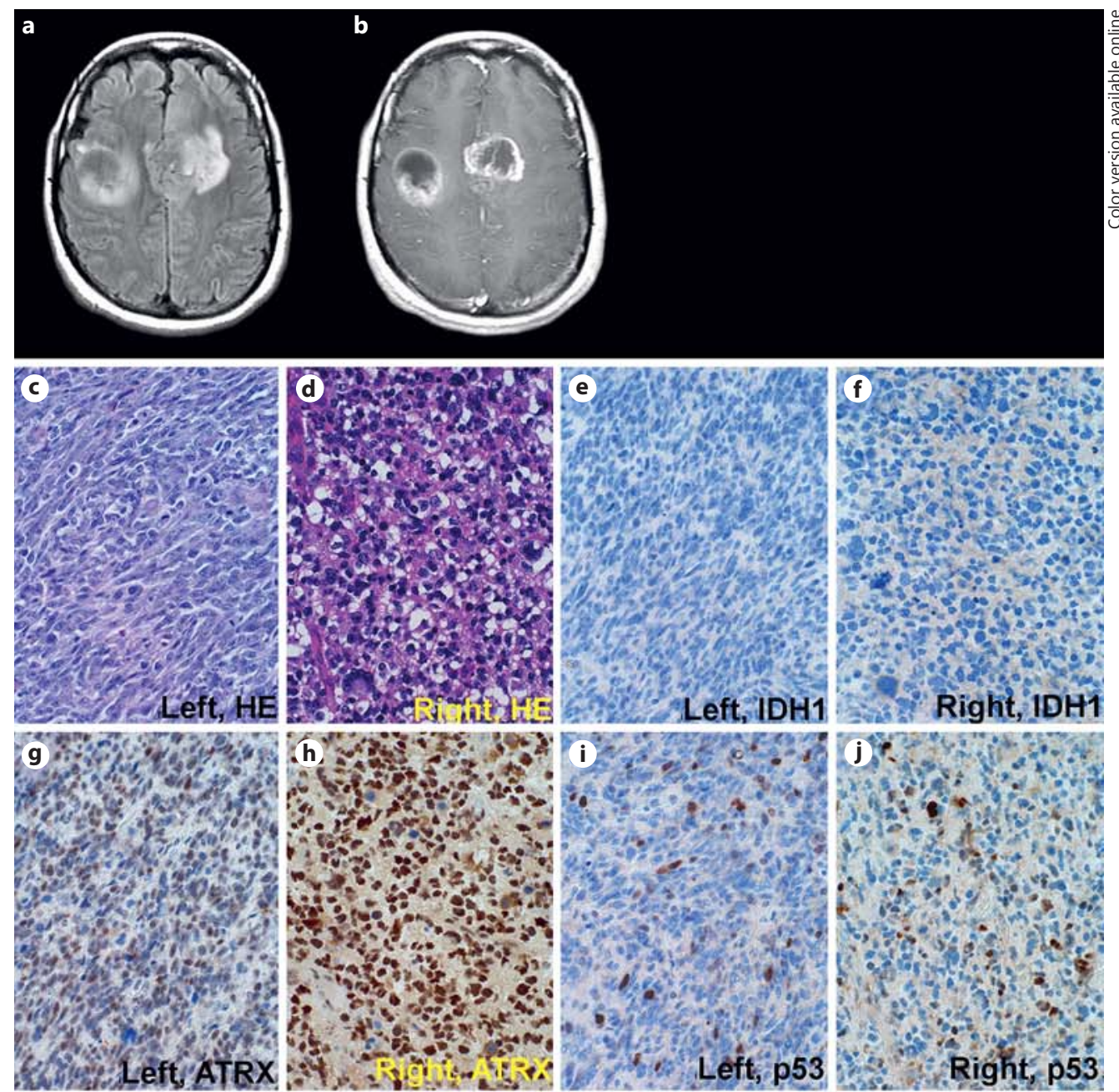

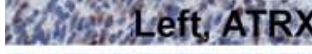
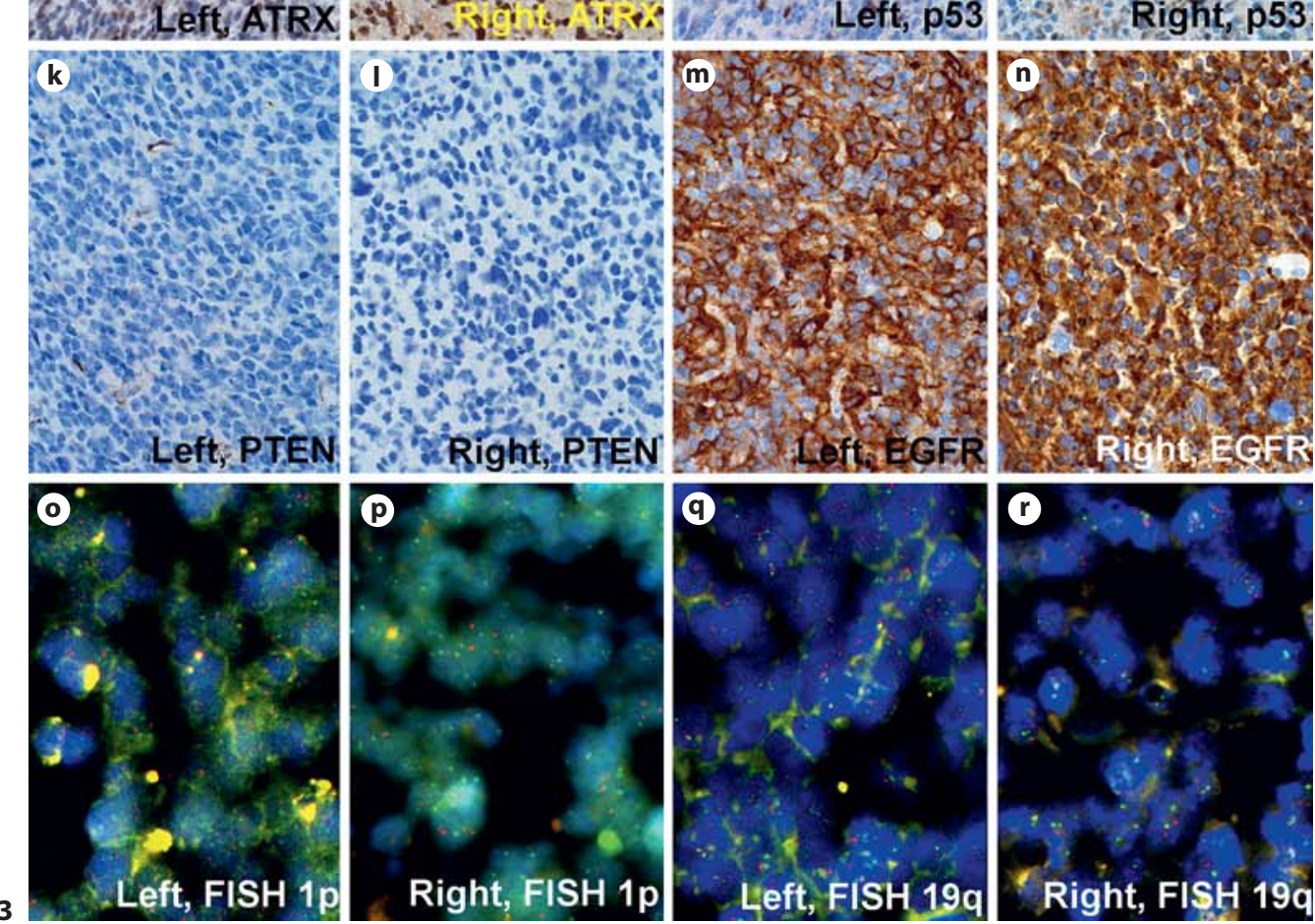

Multicentric Glioma Develops via a

Mutant IDH1-Independent Pathway

Pathobiology 2017;84:99-107 
cases were negative for mutant IDH1 staining. Most of them showed neither ATRX immunonegativity nor $1 \mathrm{p} 19 \mathrm{q}$ codeletion, and were negative for p53 staining. Based on the above typing of lower-grade gliomas, our current findings categorize multicentric gliomas as type 3 and suggest the involvement of a pathway different from that of mutant IDH-positive lower-grade gliomas and secondary glioblastomas. This type was also categorized by Gorovets et al. [39] as a preglioblastoma subclass, featuring wild-type IDH1 with molecular and clinical characteristics similar to primary glioblastoma [14, 39]. Despite their similar characteristics, the relationship between lower-grade glioma type III and primary glioblastoma has not been conclusively determined. There is evidence that different mechanisms are involved in wildtype IDH1 lower-grade gliomas and tumors manifesting mutant IDH1 or IDH2 $[14,15,39]$. This suggests that multicentric gliomas exhibit characteristics, due to their mutant IDH1 negativity, that are different from those of mutant IDH1 gliomas.

In primary glioblastoma, EGFR is strongly expressed due to its growth-factor-related activation of PI3K by which phosphatidylinositol $(3,4,5)$-triphosphate (PIP3) is formed from phosphatidylinositol $(3,4)$-bisphosphate (PIP2) phosphorylation and is activated downstream of Akt. Therefore, it is involved in cellular functions such as cell cycle progression and proliferation [40-43]. Cytoplasmic PTEN dephosphorylates PIP3 into PIP2 [44], resulting in the disruption of functions elicited by Akt regulation [40, 41, 45, 46]. Nuclear PTEN regulates entry into the cell cycle from G1 and mediates cell-cycle arrest and apoptosis $[47,48]$. In most of our cases, EGFR was overexpressed and PTEN was negative, indicating high EGFR activity and destabilization of the modulation functions of PTEN. EGFR activation and PTEN deletion are changes in the RTK/PI3K signaling that are seen in primary glioblastomas [49]. Regardless of tumor grading, such alterations are related to type III criteria $[14,15,39]$.

Glioblastoma has different characteristics and a different pathogenesis from the solitary ones [33]. In lowergrade multicentric gliomas, the predominant characteristics and pathogenesis are those of primary glioblastoma. This phenomenon differentiates multicentric glioma from the majority of mutant IDH1-immunopositive solitary lower-grade gliomas and secondary glioblastomas. Our findings suggest that the nature of multicentric gliomas is different from that of solitary gliomas and might require different management and therapeutic approaches.

Our study has some limitations. Our sample size was small and in all but 2 patients only one lesion was sampled. We did not perform DNA sequencing for mutant IDH1 analysis and cannot rule out the possibility of other minor IDH mutations: mutant IDH2 and rare-type mutant IDH1, e.g. R132C, R132L, R132S, R132G, including wild-type IDH1. We also did not perform sequence analysis of ATRX and TP53. Further studies including DNA sequencing are necessary to draw more reliable conclusions considering complex mechanisms involved in the gene status and protein expression of gliomagenesis.

\section{Acknowledgements}

We thank Ursula Petralia for editorial review. This study was partially supported by a grant-in-aid from the Japan Society for the Promotion of Science Grant-in-Aid for Scientific Research (C) No. 16K10757.

\section{Disclosure Statement}

The authors do not report any conflicts of interest.

\section{References}

1 Batzdorf U, Malamud N: The problem of multicentric gliomas. J Neurosurg 1963;20:122136.

2 Djalilian HR, Shah MV, Hall WA: Radiographic incidence of multicentric malignant gliomas. Surg Neurol 1999;51:554-558.

3 Barnard RO, Geddes JF: The incidence of multifocal cerebral gliomas: a histologic study of large hemisphere sections. Cancer 1987;60: 1519-1531.
4 Salvati M, Caroli E, Orlando ER, Frati A, Artizzu S, Ferrante L: Multicentric glioma: our experience in 25 patients and critical review of the literature. Neurosurg Rev 2003;26:275279.

5 di Russo P, Perrini P, Pasqualetti F, Meola A, Vannozzi R: Management and outcome of high-grade multicentric gliomas: a contemporary single-institution series and review of the literature. Acta Neurochir (Wien) 2013;155: 2245-2251.
6 Hefti M, von Campe G, Schneider C, Roelcke $\mathrm{U}$ : Multicentric tumor manifestations of high grade gliomas: independent proliferation or hallmark of extensive disease? Cent Eur Neurosurg 2010;71:20-25.

7 Thomas RP, Xu LW, Lober RM, Li G, Nagpal $S$ : The incidence and significance of multiple lesions in glioblastoma. J Neurooncol 2013; 112:91-97. 
8 Budka H, Podreka I, Reisner T, Zeiler K: Diagnostic and pathomorphological aspects of glioma multiplicity. Neurosurg Rev 1980;3:233241.

9 Louis DN, Perry A, Burger P, Ellison DW, Reifenberger $\mathrm{G}$, von Deimling A, et al: International Society of Neuropathology-Haarlem Consensus guidelines for nervous system tumor classification and grading. Brain Pathol 2014;24:429-435.

10 Appin CL, Brat DJ: Molecular pathways in gliomagenesis and their relevance to neuropathologic diagnosis. Adv Anat Pathol 2015; 22:50-58.

11 Reuss DE, Sahm F, Schrimpf D, Wiestler B, Capper D, Koelsche C, et al: ATRX and IDH1$\mathrm{R} 132 \mathrm{H}$ immunohistochemistry with subsequent copy number analysis and IDH sequencing as a basis for an 'integrated' diagnostic approach for adult astrocytoma, oligodendroglioma and glioblastoma. Acta Neuropathol (Berl) 2015;129:133-146.

12 Agnihotri S, Aldape KD, Zadeh G: Isocitrate dehydrogenase status and molecular subclasses of glioma and glioblastoma. Neurosurg Focus 2014;37:E13.

13 Ohgaki H, Kleihues P: The definition of primary and secondary glioblastoma. Clin Cancer Res 2013;19:764-772.

14 The Cancer Genome Atlas Research Network, Brat DJ, Verhaak RG, Aldape KD, Yung WK, Salama SR, et al: Comprehensive, integrative genomic analysis of diffuse lower-grade gliomas. N Engl J Med 2015;372:2481-2498.

15 Suzuki H, Aoki K, Chiba K, Sato Y, Shiozawa Y, Shiraishi Y, et al: Mutational landscape and clonal architecture in grade II and III gliomas. Nat Genet 2015;47:458-468.

16 Louis DN, Ohgaki H, Wiestler OD, Cavenee WK, Burger PC, Jouvet A, et al: The 2007 WHO classification of tumours of the central nervous system. Acta Neuropathol (Berl) 2007;114:97-109.

17 Louis DN, Ohgaki H, Wiestler O, Cavenee WK, Ellison DW, Figarella-Branger D, et al: WHO Classification of Tumours of the Central Nervous System, ed 4, revised. Lyon, International Agency for Research on Cancer (IARC), 2016.

18 Takami H, Yoshida A, Fukushima S, Arita H, Matsushita Y, Nakamura T, et al: Revisiting TP53 mutations and immunohistochemistry: a comparative study in 157 diffuse gliomas. Brain Pathol 2015;25:256-265.

19 Capper D, Weissert S, Balss J, Habel A, Meyer $J$, Jäger $\mathrm{D}$, et al: Characterization of $\mathrm{R} 132 \mathrm{H}$ mutation-specific IDH1 antibody binding in brain tumors. Brain Pathol 2010;20:245-254.

20 Wiestler B, Capper D, Holland-Letz T, Korshunov A, von Deimling A, Pfister SM, et al: ATRX loss refines the classification of anaplastic gliomas and identifies a subgroup of IDH mutant astrocytic tumors with better prognosis. Acta Neuropathol (Berl) 2013;126: 443-451.

21 Idoate MA, Soria E, Lozano MD, Sola JJ, Panizo A, de Alava E, et al: PTEN protein expression correlates with PTEN gene molecular changes but not with VEGF expression in astrocytomas. Diagn Mol Pathol 2003;12:160-165.

22 Shinojima N, Tada K, Shiraishi S, Kamiryo T, Kochi M, Nakamura H, et al: Prognostic value of epidermal growth factor receptor in patients with glioblastoma multiforme. Cancer Res 2003;63:6962-6970.

23 Skjulsvik AJ, Mørk JN, Torp MO, Torp SH: Ki-67/MIB-1 immunostaining in a cohort of human gliomas. Int J Clin Exp Pathol 2014;7: 8905-8910.

24 Woehrer A, Sander P, Haberler C, Kern S, Maier $\mathrm{H}$, Preusser $\mathrm{M}$, et al: FISH-based detection of $1 \mathrm{p} 19 \mathrm{q}$ codeletion in oligodendroglial tumors: procedures and protocols for neuropathological practice - a publication under the auspices of the Research Committee of the European Confederation of Neuropathological Societies. Clin Neuropathol 2011;30:47-55.

25 Mur P, Mollejo M, Hernández-Iglesias T, de Lope ÁR, Castresana JS, García JF, et al: Molecular classification defines 4 prognostically distinct glioma groups irrespective of diagnosis and grade. J Neuropathol Exp Neurol 2015; 74:241-249.

26 Gillet E, Alentorn A, Doukouré B, Mundwiller E, van Thuij H, Reijneveld JC, et al: TP53 and p53 statuses and their clinical impact in diffuse low grade gliomas. J Neurooncol 2014;118: 131-139.

27 Yan H, Parsons DW, Jin G, McLendon R, Rasheed BA, Yuan W, et al: IDH1 and IDH2 mutations in gliomas. N Engl J Med 2009;360: 765-773.

28 Hartmann C, Meyer J, Balss J, Capper D, Mueller W, Christians A, et al: Type and frequency of IDH1 and IDH2 mutations are related to astrocytic and oligodendroglial differentiation and age: a study of 1,010 diffuse gliomas. Acta Neuropathol (Berl) 2009;118: 469-474.

29 Arita H, Narita Y, Yoshida A, Hashimoto N, Yoshimine T, Ichimura K: IDH1/2 mutation detection in gliomas. Brain Tumor Pathol 2014;32:79-89.

30 Brennan CW, Verhaak RGW, McKenna A, Campos B, Noushmehr H, Salama SR, et al: The somatic genomic landscape of glioblastoma. Cell 2013;155:462-477.

31 Jiao Y, Killela PJ, Reitman ZJ, Rasheed BA, Heaphy CM, de Wilde RF, et al: Frequent ATRX, CIC, FUBP1 and IDH1 mutations refine the classification of malignant gliomas. Oncotarget 2012;3:709-722.

32 Kannan K, Inagaki A, Silber J, Gorovets D, Zhang J, Kastenhuber ER, et al: Whole-exome sequencing identifies ATRX mutation as a key molecular determinant in lower-grade glioma. Oncotarget 2012;3:1194-1203.

33 Liu Q, Liu Y, Li W, Wang X, Sawaya R, Lang FF, et al: Genetic, epigenetic, and molecular landscapes of multifocal and multicentric glioblastoma. Acta Neuropathol (Berl) 2015; 130:587-597.

34 Watanabe T, Nobusawa S, Kleihues P, Ohgaki $\mathrm{H}$ : IDH1 mutations are early events in the de- velopment of astrocytomas and oligodendrogliomas. Am J Pathol 2009;174:1149-1153.

35 Sahm F, Reuss D, Koelsche C, Capper D, Schittenhelm J, Heim S, et al: Farewell to oligoastrocytoma: in situ molecular genetics favor classification as either oligodendroglioma or astrocytoma. Acta Neuropathol (Berl) 2014;128:551-559.

36 Ichimura K, Pearson DM, Kocialkowski S, Bäcklund LM, Chan R, Jones DT, et al: IDH1 mutations are present in the majority of common adult gliomas but rare in primary glioblastomas. Neuro Oncol 2009;11:341-347.

37 Mellai M, Piazzi A, Caldera V, Monzeglio O, Cassoni P, Valente G, et al: IDH1 and IDH2 mutations, immunohistochemistry and associations in a series of brain tumors. J Neurooncol 2011;105:345-357.

38 Nakada M, Kita D, Watanabe T, Hayashi Y, Teng L, Pyko IV, et al: Aberrant signaling pathways in glioma. Cancers 2011;3:3242-3278.

39 Gorovets D, Kannan K, Shen R, Kastenhuber ER, Islamdoust N, Campos C, et al: IDH mutation and neuroglial developmental features define clinically distinct subclasses of lower grade diffuse astrocytic glioma. Clin Cancer Res 2012;18:2490-2501.

40 Jiang BH, Liu LZ: PI3K/PTEN signaling in tumorigenesis and angiogenesis. Biochim Biophys Acta 2008;1784:150-158.

41 McCubrey JA, Steelman LS, Abrams SL, Lee JT, Chang F, Bertrand FE, et al: Roles of the RAF/ MEK/ERK and PI3K/PTEN/AKT pathways in malignant transformation and drug resistance. Adv Enzyme Regul 2006;46:249-279.

42 Krakstad C, Chekenya M: Survival signalling and apoptosis resistance in glioblastomas: opportunities for targeted therapeutics. Mol Cancer 2010;9:135

43 Biernat W, Huang H, Yokoo H, Kleihues P, Ohgaki H: Predominant expression of mutant EGFR (EGFRvIII) is rare in primary glioblastomas. Brain Pathol 2004;14:131-136.

44 Maehama T, Dixon JE: The Tumor suppressor, PTEN/MMAC1, dephosphorylates the lipid second messenger, phosphatidylinositol 3,4,5-trisphosphate. J Biol Chem 1998;273: 13375-13378

45 Ohgaki H, Kleihues P: Genetic alterations and signaling pathways in the evolution of gliomas. Cancer Sci 2009;100:2235-2241.

46 Koul D: PTEN Signaling pathways in glioblastoma. Cancer Biol Ther 2008;7:1321-1325.

47 Nakamura N, Ramaswamy S, Vazquez F, Signoretti S, Loda M, Sellers WR: Forkhead transcription factors are critical effectors of cell death and cell cycle arrest downstream of PTEN. Mol Cell Biol 2000;20:8969-8982.

48 Baeza N, Weller M, Yonekawa Y, Kleihues P, Ohgaki H: PTEN methylation and expression in glioblastomas. Acta Neuropathol (Berl) 2003;106:479-485.

49 McLendon R, Friedman A, Bigner D, Meir EGV, Brat DJ, Mastrogianakis GM, et al: Comprehensive genomic characterization defines human glioblastoma genes and core pathways. Nature 2008;455:1061-1068.
Multicentric Glioma Develops via a Mutant IDH1-Independent Pathway 